\title{
An 8-week diet high in cereal fiber and coffee but free of red meat does not improve beta-cell function in patients with type 2 diabetes mellitus: a randomized controlled trial
}

Yanislava Karusheva ${ }^{1,2}$, Lejla Kunstein ${ }^{1,2,3}$, Alessandra Bierwagen ${ }^{1,2}$, Bettina Nowotny ${ }^{1,2}$, Stefan Kabisch 2,4,5, Jan B. Groener ${ }^{6}$, Ann Kristin Fleitmann ${ }^{1}$, Christian Herder ${ }^{1,2}$, Giovanni Pacini ${ }^{7}$, Klaus Strassburger ${ }^{2,8}$, Hans-Ulrich Häring ${ }^{2,9}$, Peter P. Nawroth ${ }^{6}$, Andreas F. H. Pfeiffer ${ }^{2,4,5}$, Volker Burkart ${ }^{1,2}$, Karsten Müssig ${ }^{1,2,3}$, Michael Roden ${ }^{1,2,3}$ and Julia Szendroedi ${ }^{1,2,3^{*}}$ (D)

\begin{abstract}
Background: Higher dietary intake of fibers and coffee, but lower red meat intake is associated with reduced risk for type 2 diabetes in epidemiological studies. We hypothesized that a calorie-restricted diet, which is high in fiber and coffee, but free of red meat, improves beta-cell function in patients with T2D.

Methods: In a randomized parallel-group pilot trial, obese type 2 diabetes patients were randomly allocated to consume either a diet high in cereal fiber and coffee, but free of red meat $(n=17)$ (L-RISK) or a diet low in fiber, free of coffee but high in red meat $(n=20)(H-R I S K)$ for 8 weeks. Insulin secretion was assessed from glucagon stimulation tests (GST) and mixed-meal tolerance tests (MMTT) before and after dietary intervention.

Results: Both diets resulted in comparable reduction of fasting concentrations of insulin (H-RISK -28\% vS. L-RISK -32\%, both $p<0.01$ ), C-peptide (H-RISK -26\% vs. L-RISK -30\%, both $p<0.01$ ) and blood glucose (H-RISK $-6.8 \%, p<0.05$ vs. L-RISK - $10 \%, p<0.01)$. Gastric inhibitory peptide (GIP) secretion increased by $24 \%$ after 8 weeks in the L-RISK only $(p<0.01)$. However, GST and MMTT showed no differences in insulin secretion after intervention.
\end{abstract}

Conclusions: Calorie restriction independent of the intake of fiber, coffee or meat failed to improve beta-cell function, but improved GIP secretion in obese patients with type 2 diabetes.

Trial registration: Registration at Clinicaltrials.gov, Identifier number: NCT01409330, Registered 4 August 2011 Retrospectively registered.

Keywords: Calorie restriction, Coffee, Dietary fiber, Red meat, Beta-cell function

\footnotetext{
* Correspondence: julia.szendroedi@ddz.uni-duesseldorf.de Michael Roden and Julia Szendroedi shared last co-authorship. Yanislava Karusheva and Lejla Kunstein contributed equally to this work ${ }^{1}$ Institute for Clinical Diabetology, German Diabetes Center, Leibniz Center for Diabetes Research at Heinrich Heine University Düsseldorf, Auf'm Hennekamp 65, 40225 Düsseldorf, Germany

${ }^{2}$ German Center for Diabetes Research (DZD), München-Neuherberg, Ingolstädter Landstr. 1, 85764 Neuherberg, Germany

Full list of author information is available at the end of the article
}

(C) The Author(s). 2018 Open Access This article is distributed under the terms of the Creative Commons Attribution 4.0 International License (http://creativecommons.org/licenses/by/4.0/), which permits unrestricted use, distribution, and reproduction in any medium, provided you give appropriate credit to the original author(s) and the source, provide a link to the Creative Commons license, and indicate if changes were made. The Creative Commons Public Domain Dedication waiver (http://creativecommons.org/publicdomain/zero/1.0/) applies to the data made available in this article, unless otherwise stated. 


\section{Background}

Epidemiological studies provided evidence that high fiber, high coffee intake or reduced red meat consumption may delay the onset of type 2 diabetes (T2D) and have beneficial effects on mechanisms underlying its pathogenesis [1-4]. Among others, these dietary components were used to calculate the probability of developing T2D in the European Prospective Investigation into Cancer and Nutrition (EPIC)-Potsdam study [5]. Protein- and fiber-rich products, alongside with caffeic acid and others were shown to enhance insulin secretion, whereas restriction from red meat proved to be a risk-reducing factor for the development of T2D [6-8]. The addition of fiber to a proinflammatory high-fat high-calorie meal had beneficial anti-inflammatory and metabolic effects [9]. Moreover, a high-fiber diet for 16 weeks decreased concentrations of fasting glucose [10], but also acute intake attenuated hyperglycemia [11].

Despite the mostly consistent epidemiological data, intervention studies revealed more diverse results. Indeed, acute coffee consumption shows variable health effects from those achieved by long-term consumption. One single cup of coffee aggravated postprandial glucose excursion in healthy individuals and in patients with T2D [12], whereas regular coffee intake did not influence glucose homeostasis despite its anti-inflammatory effects [13]. Moreover, the EPIC-Potsdam revealed an association between higher red meat consumption and increased risk for T2D [5]. Habitual excess meat intake can cause inflammatory responses as well as oxidative stress [14-17]. In a randomized controlled study, patients with T2D, who abstained from red meat consumption over 4 weeks, showed an increased proportion of serum polyunsaturated fatty acids, which may have a favorable effect on endothelial function, coronary artery disease and albuminuria [18]. Positive associations between red meat consumption and the risk of T2D was evident for both processed and unprocessed preparations [19]. Elevated postprandial amino acid concentrations stimulate insulin secretion without affecting glycaemia [20]. However, diets high in protein from animal or plant sources reduced hepatic fat, hepatic necroinflammation and insulin resistance [21]. Moderately supplementing meat protein with soy protein resulted in improvement of insulin sensitivity as well as total and LDL cholesterol [22]. While these studies tested the effects of single dietary modifications on metabolism, we recently reported on the comparison of two low-energy diets differing in coffee, fiber as well as red meat intake [23, 24]. Both diets equally improved insulin sensitivity and cardiac vagal function in relation to improved oxidative glucose utilization, but failed to affect insulin secretion during an intravenous glucose tolerance test in obese patients with T2D. This test reflects only the glucose-dependent component of insulin secretion under intravenous rather than oral glucose loading conditions, thereby excluding the role of glucagon, incretins and combined effects of other nutrients on in vivo beta-cell function [25]. We hypothesized that a calorie-restricted diet, high in fiber and coffee, but free of red meat, according to the German Diabetes Risk Score (GDRS), improves beta-cell function as assessed by insulin secretion in patients with T2D. To investigate the hypothesis we used both glucagon stimulation and mixed-meal tolerance tests which are established methods for evaluating beta-cell secretory capacity in T2D [26].

\section{Methods}

\section{Patients and study design}

This study was performed in a subgroup of participants of a randomized controlled parallel group trial [23, 24], who underwent two additional tests for beta-cell function on two different days spaced by 8 weeks. Type 2 diabetes patients (18-69 years of age, body mass index (BMI) $\geq 30 \mathrm{~kg} / \mathrm{m}^{2}$, known diabetes duration $\leq 5$ years), treated by lifestyle changes and/or with metformin and/ or acarbose were included. Exclusion criteria comprised HbAlc $>75 \mathrm{mmol} / \mathrm{mol}(9.0 \%)$, diabetes types other than T2D and acute or chronic diseases including inflammatory diseases or cancer. Patients taking any medication affecting the immune system or insulin sensitivity, other than metformin, were also excluded.

The details of the protocol have been reported elsewhere [23]. A total of 37 obese patients with T2D completed this trial (Additional file 1: Figure S1). A time line of all experiments is given in Additional file 2: Figure S2. The primary endpoint was the M-value derived from the hyperinsulinemic euglycemic clamp test to assess whole-body insulin sensitivity. Based on previously re-

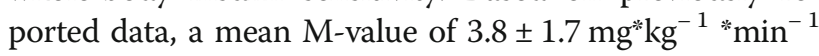
was expected prior to the start of the intervention. For every percentage increase of the $\mathrm{M}$-value, the ratio between the percentage increase of the M-value in the L-RISK group and the percentage increase in the H-RISK group was calculated. Assuming a $20 \%$ increase in L-RISK and $16 \%$ increase in H-RISK gives a ratio of 1.2 with a conservative estimate of a coefficient of variation of 0.3 and an intraindividual correlation of 0.7. This calculation yields a statistical power of $91 \%$. In order to ensure sufficient numbers of patients per group, we recruited 29/30 persons per group (Additional file 1: Figure S1). The given number of analysed participants of $n=15-19$ (H-RISK) und $n=13-16$ (L-RISK) allows detecting moderate effect sizes (Cohen's $\mathrm{d}=0.8$ ) for baseline and 8 week-follow-up 
differences of measures of beta-cell function from MMT with a power of at least $80 \%$. Thus, the present study was sufficiently powered to detect changes in beta-cell function.

The participants were either assigned to a diet low in fiber $(\leq 10 \mathrm{~g} /$ day), coffee-free and high in red meat ( $\geq 150 \mathrm{~g} /$ day) (H-RISK, $n=20)$ or to a diet high in cereal fiber from wheat and rye (100 g of wholegrain crispread and $250-300 \mathrm{~g}$ of wheat/rye wholegrain bread) and fresh-brewed coffee ( $\geq 5$ cups/day containing 7-8g coffee powder each, the standard size of coffee cups is $125-150 \mathrm{ml}$ in Europe [5]) and free of red meat (L-RISK, $n=17$ ). All participants gave written informed consent before inclusion in the study. The study was performed according to the Declaration of Helsinki, approved by the ethics committee of the Medical Faculty of Heinrich Heine University Düsseldorf and registered at clinicaltrials.gov (Identifier number: NCT01409330).

\section{Dietary monitoring}

Before the start of the intervention, the participants documented their nutritional behavior. During the intervention, all participants received individually calculated daily nutritional protocols, which they had to follow and were asked to document any changes. They had to return the completed sheets to monitor compliance. During the intervention, individually documented food intake was used to assess the participants' adherence to the study protocol and to ensure consistency of food intake.

\section{Mixed-meal tolerance test}

After overnight fasting for $12 \mathrm{~h}$, participants ingested a standardized liquid meal $\left(237 \mathrm{ml}\right.$ Boost $^{\circ}$ High Protein, Nestle HealthCare Nutrition, Inc., Florham Park, NJ, USA) containing $33 \mathrm{~g}$ carbohydrates, $6 \mathrm{~g}$ fat and $15 \mathrm{~g}$ protein within $5 \mathrm{~min}$ starting at zero time. Blood samples were taken at $\min -15,0,+30,+60,+90,+120$ and + 180 for measurements of glucose, insulin and C-peptide levels to calculate incremental areas under the curve (iAUC), using the trapezoidal rule after subtracting the basal (fasting) values. Insulinogenic index (IGI) was calculated for assessing beta-cell function from the ratio of the difference between insulin levels at baseline and at $30 \mathrm{~min}$ to the same difference for glucose levels [27]. The mean basal values of blood glucose and insulin have been previously reported [23].

\section{Glucagon stimulation test}

After overnight fasting for $12 \mathrm{~h}$, blood samples were obtained for measurements of fasting glucose, insulin and C-peptide levels. At zero time, a bolus of $1 \mathrm{mg}$ glucagon (GlucaGen; Novo Nordisk, Mainz, Germany) was injected intravenously and a second blood sample was obtained at $\min +6$ for measurements of insulin and C-peptide levels [26]. The difference between $\mathrm{C}$-peptide and insulin concentrations between $0 \mathrm{~min}$ and $6 \mathrm{~min}$ was used to assess glucagon-stimulated C-peptide and insulin secretion capacities ( $\Delta \mathrm{C}$-peptide and $\Delta$ insulin, respectively) [28].

\section{Laboratory analyses}

Serum samples were analyzed as described [26]. Briefly, blood glucose concentration was measured by the hexokinase method (EPOS 5060 analyzer; Eppendorf, Hamburg, Germany). Serum C-peptide and insulin were measured by radioimmunoassay (intra-assay coefficient of variation $(\mathrm{CV})$ for all, $1 \%$; interassay $\mathrm{CV}, 6-7 \%$ and 5-9\%, respectively; Millipore, St. Charles, MO, USA) [29]. Glucagon-like peptide 1 (GLP-1) and gastric inhibitor peptide (GIP) were measured using ELISA (GLP-1: interassay CV, 10\%; TECOmedical, Sissach, Switzerland; GIP: interassay CV, 12\%; Millipore) [29]. Other parameters of clinical chemistry (total cholesterol, low-density lipoprotein (LDL), high-density lipoprotein (HDL) and triglycerides (TG)) as well as liver enzymes were measured on a Cobas c311 analyzer (Roche, Diagnostics, Mannheim, Germany) [26].

\section{Statistical analyses}

The values are shown as mean \pm standard error of the mean (SEM). Assuming that the two experimental samples follow Gaussian distribution, statistical significance of differences was assessed with the two-tailed $t$-test. The effects of both diets on blood glucose and incretin levels and on parameters reflecting insulin secretion were analyzed by repeated measurement two-way ANOVA to compare diet-induced changes between groups as well as effects of time, diet and time - diet interaction. Analyses adjusted for BMI, weight loss and medication were performed to exclude these as confounding factors.

\section{Results \\ Anthropometry}

Patients in both H-RISK and L-RISK groups did not differ in age, body mass index, glycemic control and lipidemia and had comparable blood glucose-lowering medications [23].

\section{Dietary composition and body weight}

At baseline, all participants of both groups had comparable calorie, macronutrient, red meat, coffee and cereal fiber intake. All participants adhered to the nutritional protocols as evident by a 6.9-fold higher intake of cereal fiber in the L-RISK group $(p<0.0001)$, a 1.3 -fold higher intake of red meat and the absence of coffee consumption in the H-RISK group compared to the L-RISK group (both $p<0.0001$ ). As a result of the dietary advice, participants of both groups consumed less total energy 
and fat, but more carbohydrates and proteins during the intervention [23].

\section{Mixed-meal-stimulated beta-cell function}

At baseline, fasting glucose, insulin and C-peptide (Fig. 1a, c, e) as well as GLP-1 and GIP were similar between both groups. Fasting blood glucose levels measured on the day of the MMTT decreased by $10 \%(-11.9 \pm 2.8 \mathrm{mg} / \mathrm{dl}, p<0.01)$ in the L-RISK group and by $6.8 \%(-7.9 \pm 2.9 \mathrm{mg} / \mathrm{dl}, p<0.05)$ in the H-RISK group (Fig. 1a). Previously reported blood glucose levels were measured on the day of the hyperinsulinemic euglycemic clamp test (HEC), as insulin sensitivity was the primary endpoint [23]. Fasting blood glucose levels assessed before MMTT were not different compared to those measured before HEC ( $p>0.05$ for both groups). Fasting insulin concentration decreased by $28 \%(-5.1 \pm 1.4 \mu \mathrm{U} / \mathrm{ml}$, $p<0.01)$ in the H-RISK group and by $32 \%(-6.8 \pm 1.9$ $\mu \mathrm{U} / \mathrm{ml}, p<0.01$ ) in the L-RISK group (Fig. 1c). Fasting C-peptide concentration decreased by $26 \%(-0.8$ $\pm 0.2 \mathrm{ng} / \mathrm{ml}, p<0.01)$ in the H-RISK group and by $30 \%(-1.0 \pm 0.3 \mathrm{ng} / \mathrm{ml}, p<0.01)$ in the L-RISK group (Fig. 1e). There were no differences of the changes in fasting glucose and hormone concentrations between both groups. IGI remained unchanged in the H-RISK group before $(138.5 \pm 15.0)$ and after $(141.2 \pm 24.9)$ as well as in the L-RISK group before $(176.0 \pm 20.0)$ and after $(206.6 \pm 43.2)$ dietary intervention, showing no change in beta-cell function.

At baseline, iAUC for glucose, insulin, C-peptide, GLP-1 and GIP (Fig. 1b, d, f, g, h) were similar between both groups. After dietary intervention, iAUC for glucose decreased by $20 \%\left(-1109 \pm 507 \mathrm{mg} / \mathrm{dl}^{*} 180 \mathrm{~min}, p<0.05\right)$ only in the H-RISK group (Fig. 1b). The iAUC for insulin and C-peptide (Fig. 1d, f) neither changed during L-RISK nor during H-RISK diets. The iAUC for GIP increased only after the L-RISK diet $\left(+8152 \pm 1993 \mathrm{pg} / \mathrm{ml}^{*} 180 \mathrm{~min}\right.$, $p<0.01$ ) (Fig. 1h), whereas the iAUC for GLP-1 remained unchanged after both diets. Further statistical analyses of MMTT revealed no differences in the changes of all parameters from week 0 to week 8 between the H-RISK and L-RISK groups. After adjustments for BMI, weight loss and medication, the results of the analyses remained virtually unchanged.

\section{Glucagon-stimulated beta-cell function}

In the L-RISK group, compared to the H-RISK group, $\Delta$ insulin and $\Delta \mathrm{C}$-peptide concentrations were higher before the intervention (both $p<0.01$ ) (Fig. 2a, b). In the H-RISK group, $\Delta \mathrm{C}$-peptide concentration increased by $27 \%(p<0.01)$. No changes of $\Delta$ insulin were observed in either group. After further adjustments for BMI, weight loss and medication, the results of the analyses remained virtually unchanged.

\section{Discussion}

Eight-week calorie restricted diets, differing in the intake of cereal fibers, coffee and red meat, both failed to improve mixed-meal- or glucagon-stimulated beta-cell function, but decreased fasting insulinemia in obese patients with near-normoglycemic T2D. Both EPIC and the dietary-based diabetes-risk score (DDS) [30] weighted positively low-fat dairy, fiber and coffee and negatively red meat. To design our dietary intervention, we used dietary components established as individual markers of high/low risk of T2D, but not previously used in this very combination. We cannot exclude the possibility of interaction between single dietary components. This dietary multimodal intervention, however, neither evaluated single dietary components nor focused on effects of macronutrients' components.

In healthy humans, high-fiber diet was found to enhance insulin secretion, indicating improvement of beta-cell function [6]. It is speculated that fiber-rich products contain specific compounds such as trace minerals and phenolic compounds enhancing the acute phase of insulin secretion. In fact, previous studies showed that high-fiber intake lowers the risk of type 2 diabetes [31] and improves glycemic control in patients with overt type 2 diabetes [4]. However, patients of these studies featured mostly diabetes duration of $>5$ years and markedly impaired beta-cell function. In the present study, the absence of any effect of modulating fiber intake on insulin secretion may be due to the rather preserved beta-cell function, which probably cannot be further improved by mild to moderate dietary interventions. Nevertheless, we applied an inclusion criterion for known diabetes duration $\leq 5$ years to keep the study group homogenous and the pancreatic insulin production preserved. Previous studies revealed that patients with T2D for up to 6 years duration are more likely to reach a remission of the disease through a dietary or lifestyle intervention [32,33] suggesting preserved beta-cell secretion capacity.

However, both fasting insulin and C-peptide decreased most likely corresponding to improved insulin sensitivity in both groups as previously shown [23]. In parallel, both groups showed a reduction of fasting blood glucose levels after 8 weeks of intervention, so both diets lead to reducing hyperglycemia. In the H-RISK group iAUC for glucose decreased by about $20 \%$. Furthermore, $\Delta$ C-peptide increased by about $27 \%$ in the H-RISK group only. In the absence of any changes of $\Delta$ insulin, this finding does not indicate a physiologically relevant change of insulin secretion. Of note, both $\Delta$ C-peptide and $\Delta$ insulin remained 

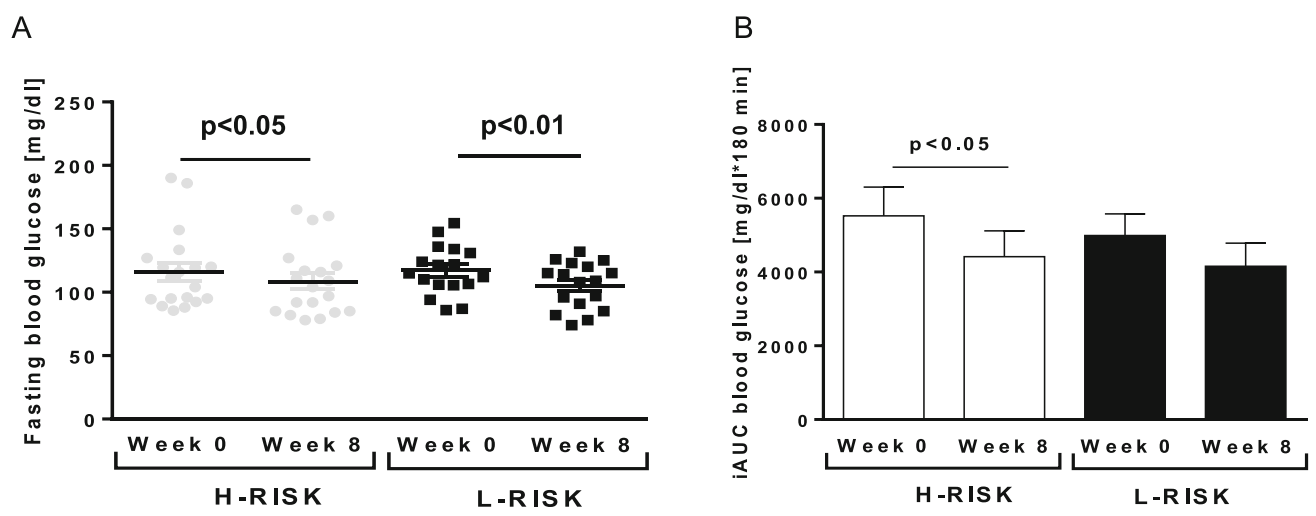

C
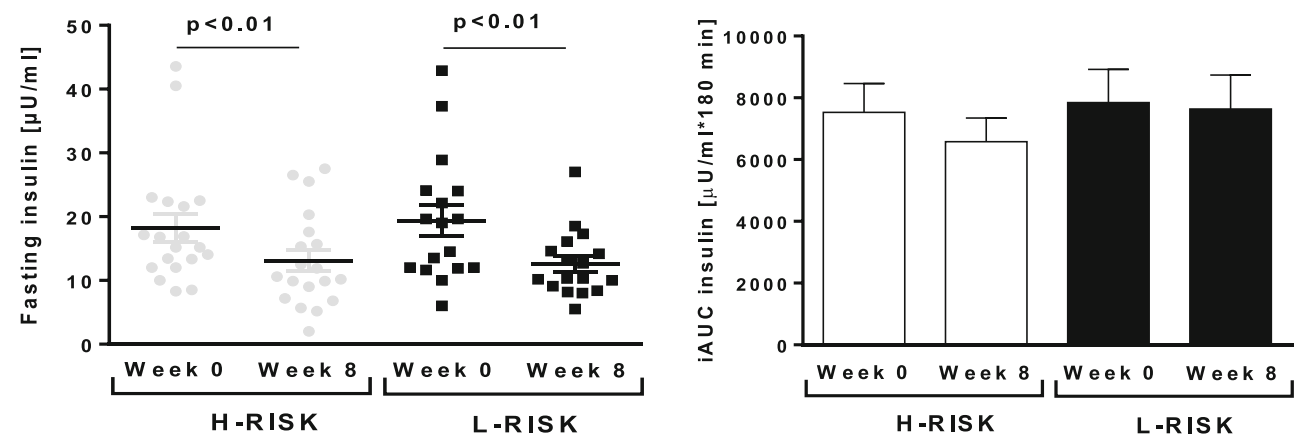

E
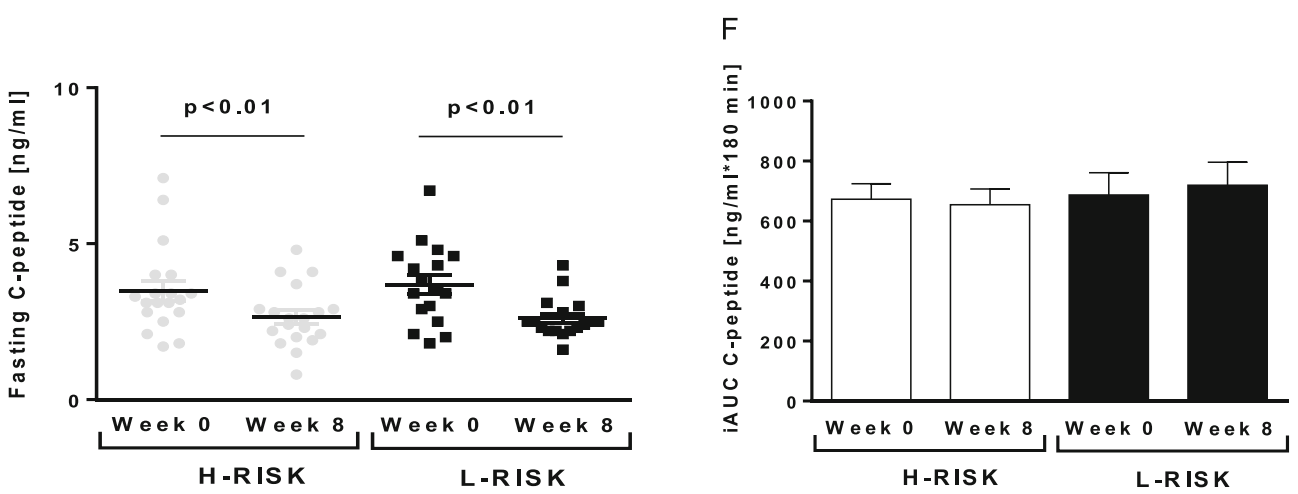

G

$\mathrm{H}$
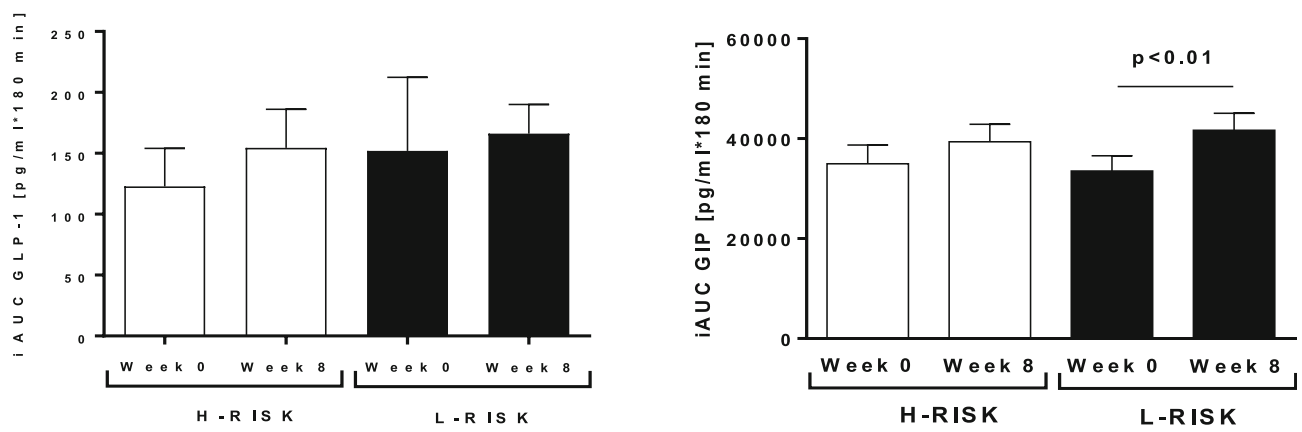

Fig. 1 Fasting concentrations of blood glucose (a), insulin (c), C-peptide (e), as well as mixed-meal-induced beta-cell function (means \pm SEM) from incremental areas under the respective concentration-time curves (iAUC; $\mathbf{b}, \mathbf{d}, \mathbf{f}$ ) before and after dietary intervention in a subgroup of participants of the H-RISK group $(n=19)$ and L-RISK groups $(n=16)$. Glucagon-like peptide (GLP-1) $(\mathbf{g})$ and gastric inhibitor peptide (GIP) (h) from incremental areas under the respective concentration-time curves 

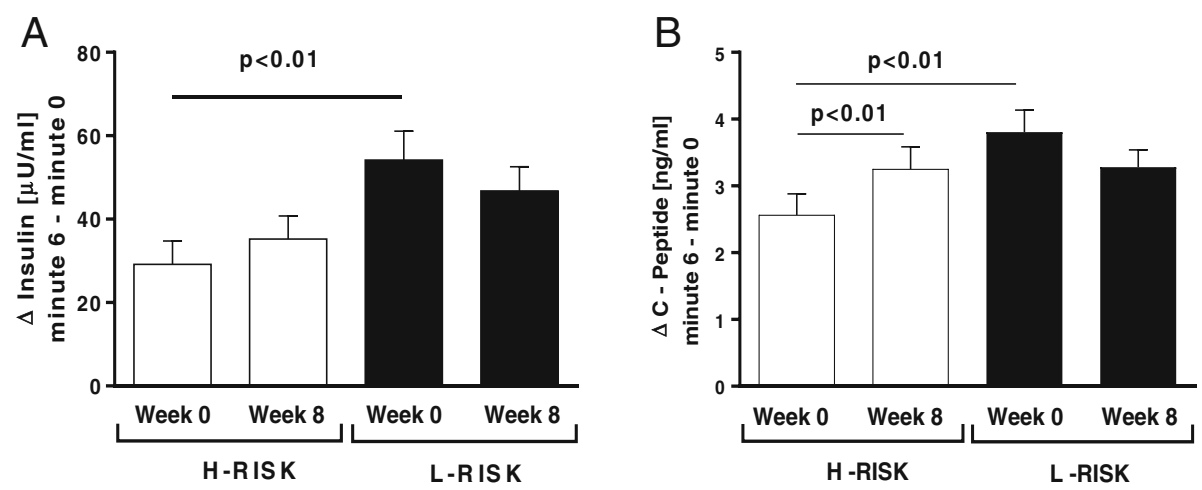

Fig. 2 Glucagon-stimulated beta-cell function (means \pm SEM) from $\Delta$ insulin (a) and $\Delta$ C-peptide (b) before and after dietary intervention in a subgroup of participants of the H-RISK $(n=15)$ and L-RISK groups $(n=13)$

unchanged in the L-RISK group. Results of observational studies support the protective effects of coffee and reduced red meat consumption [3,34, 35]. However, in the setting of our study in patients with overt T2D, these dietary factors also reduce hyperglycemia, but fail to affect insulin secretion.

Of note, coffee consumption of $\geq 5$ cups/day containing 7-8 g coffee powder each, also failed to affect insulin secretion. This is in line with cross-sectional analyses of 1440 Japanese adults using the homeostatic model assessment as a surrogate of insulin secretion [36] and of 1088 elderly Swedish men, assessing the early insulin response during an oral glucose tolerance test (OGTT) [37].

The absence of any effect of dietary modulation of fibers, coffee and meat on insulin secretion in the present study could be due to the short intervention period. In our study, 8 weeks of dietary intervention did not affect insulin and C-peptide secretion in any of the groups as assessed by MMTT. However, in the L-RISK group there was an increase of GIP concentration during MMTT after dietary intervention. This observation corresponds with the results of a previous study showing a decrease of GIP secretion after a high-fat meal, but a preservation of GIP secretion after a high-fiber meal [38].

The similar decrease in fasting insulin and C-peptide levels suggests a comparable improvement in - particularly hepatic - insulin sensitivity by both H-RISK and L-RISK diets. Our initial study preceding this subgroup analysis found that both diets increase whole body insulin sensitivity, without changes in insulin-mediated suppression of endogenous glucose production as assessed from the hyperinsulinemic euglycemic clamp test, which however was not designed to specifically test hepatic insulin sensitivity [23, 24]. Of note, both diets also lowered the increased hepatic fat content, which is generally linked to hepatic insulin resistance [39]. With regard to higher coffee consumption, the observed improvements in insulin sensitivity, but not insulin secretion are in line with some cross-sectional analyses [36, 37], but not with a randomized crossover-study in 26 healthy humans, who drank one liter coffee every day for 4 weeks [40].

The present study benefits from examining beta-cell function with two independent methods and careful dietary monitoring, but suffers from the limited intervention period of 8 weeks and the small sample sizes. In addition, this study cannot account for potential effects of different preparation and processing of macronutrients. Moreover, a disadvantage of the study was that the baseline insulin and C-peptide secretory capacity was different between the two intervention groups despite randomization. To detect further possible effects particularly on insulin secretion, the comprehensive metabolic phenotyping of a several fold higher number of participants would have been required. In addition, both dietary interventions led to a minor $(<5 \%)$ weight loss, which could have nevertheless masked certain diet-specific effects.

\section{Conclusion}

In conclusion, a short-term dietary modification with high cereal fibers and coffee, but free of red meat does not improve beta-cell function compared to a diet low in fibers, lacking coffee and high in red meat. Any reduction of hyperglycemia by both diets is not due to changes in insulin secretion.

\section{Additional files}

Additional file 1: Figure S1. Flow diagram of participants' recruitment. (PDF 203 kb)

Additional file 2: Figure S2. Time line of study protocol. (PDF $261 \mathrm{~kb}$ )

\section{Abbreviations}

AGEs: Advanced glycation end products; BMI: Body mass index; GIP: Gastric inhibitory peptide; GLP-1: Glucagon-like peptide 1; GST: Glucagon stimulation test; HEC: H-RISK, high-risk diet low in fiber, free of coffee and high in red meat; iAUC: Incremental area under the curve; IGI: Insulinogenic index; 
LDL: Low-density-lipoprotein cholesterol; L-RISK: Low-risk diet high in fiber, coffee ( $\geq 5$ cups/day) and free of red meat; MMTT: Mixed-meal tolerance test; OGTT: Oral glucose tolerance test; TMAO: Trimethylamine N-oxide

\section{Acknowledgments}

The authors appreciate the voluntary contribution of all study participants. They also thank the staff of the Clinical Research Center of the German Diabetes Center (DDZ) for excellent technical assistance and care of the patients.

\section{Funding}

The study was initiated and financed by the DDZ - German Diabetes Center which is funded by the German Federal Ministry of Health (Berlin, Germany) and the Ministry of Culture and Science of the state North Rhine-Westphalia (Düsseldorf, Germany) and from the German Federal Ministry of Education and Research (BMBF) to the German Center for Diabetes Research (DZD e.V.) and the Helmholtz Alliance Imaging and Curing Environmental Metabolic Diseases (ICEMED).

\section{Availability of data and materials}

The datasets used and/or analysed during the current study are available from the corresponding author on reasonable request.

\section{Authors' contributions}

YK and LK contributed equally to this manuscript. AB, BN, SK, JBG, AKF, CH and GP researched data. VB, KM, JS and MR contributed to the discussion and reviewed/edited the manuscript. KS performed the statistical analyses. All the authors contributed substantially to aspects of study design or the acquisition of data, contributed to drafting of the article or revised it critically for important intellectual content and gave final approval to the version to be published. JS and MR are the guarantors of this work and, as such, had full access to all the data in the study and take responsibility for the integrity of the data and the accuracy of the data analysis.

\section{Ethics approval and consent to participate}

The study was performed according to the Declaration of Helsinki, approved by the ethics committee of the Medical Faculty of Heinrich Heine University Düsseldorf. All participants gave written informed consent before inclusion in the study.

\section{Consent for publication}

All authors have seen and approved the manuscript being submitted.

\section{Competing interests}

The authors declare that they have no competing interests.

\section{Publisher's Note}

Springer Nature remains neutral with regard to jurisdictional claims in published maps and institutional affiliations.

\section{Author details}

'Institute for Clinical Diabetology, German Diabetes Center, Leibniz Center for Diabetes Research at Heinrich Heine University Düsseldorf, Auf'm Hennekamp 65, 40225 Düsseldorf, Germany. ${ }^{2}$ German Center for Diabetes Research (DZD), München-Neuherberg, Ingolstädter Landstr. 1, 85764 Neuherberg, Germany. ${ }^{3}$ Division of Endocrinology and Diabetology, Medical Faculty, Heinrich Heine University Düsseldorf, Düsseldorf, Moorenstr. 5, 40225 Düsseldorf, Germany. ${ }^{4}$ Department Clinical Nutrition, German Institute for Nutritional Research (DifE) Potsdam, Bergholz-Rehbrücke, Arthur-Scheunert-Allee 114-1, 14558 Bergholz-Rehbrücke, Germany. ${ }^{5}$ Department of Endocrinology, Diabetes and Nutrition, Charité Universitätsmedizin Berlin, Campus Benjamin Franklin, Hindenburgdamm 30, 12203 Berlin, Germany. ${ }^{6}$ Department for Internal Medicine I, University Hospital Heidelberg, Im Neuenheimer Feld 410, 69120 Heidelberg, Germany. ${ }^{7}$ Metabolic Unit, Institute of Biomedical Engineering, National Research Council, Corso Stati Uniti, 4, 35127 Padova, Italy. ${ }^{8}$ Institute for Biometrics and Epidemiology, German Diabetes Center, Leibniz Center for Diabetes Research at Heinrich Heine University Düsseldorf, Auf'm Hennekamp 65, 40225 Düsseldorf, Germany. ${ }^{9}$ Department of Internal Medicine, Division of Endocrinology, Diabetology, Vascular Medicine, Nephrology and Clinical Chemistry and Institute of Diabetes Research and Metabolic Diseases,
University Hospital Tübingen, Otfried-Müller-Straße 10, 72076 Tübingen, Germany.

Received: 30 May 2018 Accepted: 29 November 2018

Published online: 29 December 2018

\section{References}

1. van Dam RM, Hu FB. Coffee consumption and risk of type 2 diabetes: a systematic review. JAMA. 2005:294:97-104.

2. Lajous M, Tondeur L, Fagherazzi G, de Lauzon-Guillain B, Boutron-Ruaualt MC, Clavel-Chapelon F. Processed and unprocessed red meat consumption and incident type 2 diabetes among French women. Diabetes Care. 2012; 35:128-30.

3. Huxley R, Lee CM, Barzi F, Timmermeister L, Czernichow S, Perkovic V, Grobbee DE, Batty D, Woodward M. Coffee, decaffeinated coffee, and tea consumption in relation to incident type 2 diabetes mellitus: a systematic review with meta-analysis. Arch Intern Med. 2009;169:2053-63.

4. Post RE, Mainous AG 3rd, King DE, Simpson KN. Dietary fiber for the treatment of type 2 diabetes mellitus: a meta-analysis. J Am Board Fam Med. 2012:25:16-23.

5. Schulze MB, Hoffmann K, Boeing H, Linseisen J, Rohrmann S, Mohlig M, Pfeiffer AF, Spranger J, Thamer C, Haring HU, et al. An accurate risk score based on anthropometric, dietary, and lifestyle factors to predict the development of type 2 diabetes. Diabetes Care. 2007:30:510-5.

6. Juntunen KS, Laaksonen DE, Poutanen KS, Niskanen LK, Mykkanen HM. High-fiber rye bread and insulin secretion and sensitivity in healthy postmenopausal women. Am J Clin Nutr. 2003;77:385-91.

7. Weber KS, Buyken AE, Nowotny B, Strassburger K, Simon MC, Pacini G, Szendroedi J, Mussig K, Roden M. The impact of dietary factors on glycemic control, insulin sensitivity and secretion in the first years after diagnosis of diabetes. Exp Clin Endocrinol Diabetes. 2016;124:230-8.

8. Loureiro LMR, Reis CEG, da Costa THM. Effects of coffee components on muscle glycogen recovery: a systematic review. Int J Sport Nutr Exerc Metab. 2018;28:284-93.

9. Ghanim H, Batra M, Abuaysheh S, Green K, Makdissi A, Kuhadiya ND, Chaudhuri A, Dandona P. Antiinflammatory and ROS suppressive effects of the addition of fiber to a high-fat high-calorie meal. J Clin Endocrinol Metab. 2017;102:858-69.

10. Jang Y, Lee JH, Kim OY, Park HY, Lee SY. Consumption of whole grain and legume powder reduces insulin demand, lipid peroxidation, and plasma homocysteine concentrations in patients with coronary artery disease: randomized controlled clinical trial. Arterioscler Thromb Vasc Biol. 2001;21: 2065-71.

11. Kim EK, Oh TJ, Kim LK, Cho YM. Improving effect of the acute Administration of dietary fiber-enriched cereals on blood glucose levels and gut hormone secretion. J Korean Med Sci. 2016;31:222-30.

12. Krebs JD, Parry-Strong A, Weatherall M, Carroll RW, Downie M. A cross-over study of the acute effects of espresso coffee on glucose tolerance and insulin sensitivity in people with type 2 diabetes mellitus. Metabolism. 2012; 61:1231-7.

13. Kempf K, Herder C, Erlund I, Kolb H, Martin S, Carstensen M, Koenig W, Sundvall J, Bidel S, Kuha S, Tuomilehto J. Effects of coffee consumption on subclinical inflammation and other risk factors for type 2 diabetes: a clinical trial. Am J Clin Nutr. 2010;91:950-7.

14. Tang C, Koulajian K, Schuiki I, Zhang L, Desai T, Ivovic A, Wang P, RobsonDoucette C, Wheeler MB, Minassian B, et al. Glucose-induced beta cell dysfunction in vivo in rats: link between oxidative stress and endoplasmic reticulum stress. Diabetologia. 2012;55:1366-79.

15. Brun T, Li N, Jourdain AA, Gaudet P, Duhamel D, Meyer J, Bosco D, Maechler $P$. Diabetogenic milieus induce specific changes in mitochondrial transcriptome and differentiation of human pancreatic islets. Hum Mol Genet. 2015;24:5270-84

16. Maedler K, Sergeev P, Ris F, Oberholzer J, Joller-Jemelka HI, Spinas GA, Kaiser N, Halban PA, Donath MY. Glucose-induced beta cell production of IL-1 beta contributes to glucotoxicity in human pancreatic islets. J Clin Invest. 2017; 127:1589.

17. Aune D, Ursin G, Veierod MB. Meat consumption and the risk of type 2 diabetes: a systematic review and meta-analysis of cohort studies. Diabetologia. 2009;52:2277-87.

18. de Mello VD, Zelmanovitz T, Perassolo MS, Azevedo MJ, Gross JL. Withdrawal of red meat from the usual diet reduces albuminuria and 
improves serum fatty acid profile in type 2 diabetes patients with macroalbuminuria. Am J Clin Nutr. 2006;83:1032-8.

19. Pan A, Sun Q, Bernstein AM, Schulze MB, Manson JE, Willett WC, Hu FB. Red meat consumption and risk of type 2 diabetes: 3 cohorts of US adults and an updated meta-analysis. Am J Clin Nutr. 2011;94:1088-96.

20. Krebs M, Brehm A, Krssak M, Anderwald C, Bernroider E, Nowotny P, Roth E, Chandramouli V, Landau BR, WaldhausI W, Roden M. Direct and indirect effects of amino acids on hepatic glucose metabolism in humans. Diabetologia. 2003;46:917-25.

21. Markova M, Pivovarova O, Hornemann S, Sucher S, Frahnow T, Wegner K, Machann J, Petzke KJ, Hierholzer J, Lichtinghagen R, et al. Isocaloric diets high in animal or plant protein reduce liver fat and inflammation in individuals with type 2 diabetes. Gastroenterology. 2017;152:571-85 e578.

22. van Nielen M, Feskens EJ, Rietman A, Siebelink E, Mensink M. Partly replacing meat protein with soy protein alters insulin resistance and blood lipids in postmenopausal women with abdominal obesity. J Nutr. 2014;144:1423-9.

23. Nowotny B, Zahiragic L, Bierwagen A, Kabisch S, Groener JB, Nowotny PJ, Fleitmann AK, Herder C, Pacini G, Erlund I, et al. Low-energy diets differing in fibre, red meat and coffee intake equally improve insulin sensitivity in type 2 diabetes: a randomised feasibility trial. Diabetologia. 2015;58:255-64.

24. Ziegler D, Strom A, Nowotny B, Zahiragic L, Nowotny PJ, Carstensen-Kirberg M, Herder C, Roden M. Effect of low-energy diets differing in fiber, red meat, and coffee intake on cardiac autonomic function in obese individuals with type 2 diabetes. Diabetes Care. 2015;38:1750-7.

25. Carlessi R, Keane KN, Mamotte C, Newsholme P. Nutrient regulation of beta-cell function: what do islet cell/animal studies tell us? Eur J Clin Nutr. 2017;71:890-5.

26. Szendroedi J, Saxena A, Weber KS, Strassburger K, Herder C, Burkart V, Nowotny B, Icks A, Kuss O, Ziegler D, et al. Cohort profile: the German diabetes study (GDS). Cardiovasc Diabetol. 2016;15:59.

27. Tura A, Kautzky-Willer A, Pacini G. Insulinogenic indices from insulin and Cpeptide: comparison of beta-cell function from OGTT and IVGTT. Diabetes Res Clin Pract. 2006;72:298-301.

28. Greenbaum CJ, Mandrup-Poulsen T, McGee PF, Battelino T, Haastert B, Ludvigsson J, Pozzilli P, Lachin JM, Kolb H. Mixed-meal tolerance test versus glucagon stimulation test for the assessment of beta-cell function in therapeutic trials in type 1 diabetes. Diabetes Care. 2008;31:1966-71.

29. Nowotny B, Zahiragic L, Krog D, Nowotny PJ, Herder C, Carstensen M, Yoshimura T, Szendroedi J, Phielix E, Schadewaldt P, et al. Mechanisms underlying the onset of oral lipid-induced skeletal muscle insulin resistance in humans. Diabetes. 2013;62:2240-8.

30. Dominguez $\sqcup$, Bes-Rastrollo M, Basterra-Gortari FJ, Gea A, Barbagallo M, Martinez-Gonzalez MA. Association of a dietary score with incident type 2 diabetes: the dietary-based diabetes-risk score (DDS). PLoS One. 2015;10: e0141760.

31. Ye EQ, Chacko SA, Chou EL, Kugizaki M, Liu S. Greater whole-grain intake is associated with lower risk of type 2 diabetes, cardiovascular disease, and weight gain. J Nutr. 2012;142:1304-13.

32. Lean ME, Leslie WS, Barnes AC, Brosnahan N, Thom G, McCombie L, Peters C, Zhyzhneuskaya S, Al-Mrabeh A, Hollingsworth KG, et al. Primary care-led weight management for remission of type 2 diabetes (DiRECT): an openlabel, cluster-randomised trial. Lancet. 2018;391:541-51.

33. Sjostrom $L$, Peltonen $M$, Jacobson $P$, Ahlin $S$, Andersson-Assarsson J, Anveden A, Bouchard C, Carlsson B, Karason K, Lonroth H, et al. Association of bariatric surgery with long-term remission of type 2 diabetes and with microvascular and macrovascular complications. JAMA. 2014;311:2297-304.

34. Yamakado M, Nagao K, Imaizumi A, Tani M, Toda A, Tanaka T, Jinzu H, Miyano H, Yamamoto H, Daimon T, et al. Plasma free amino acid profiles predict four-year risk of developing diabetes, metabolic syndrome, dyslipidemia, and hypertension in Japanese population. Sci Rep. 2015:5:11918.

35. Cho SS, Qi L, Fahey GC Jr, Klurfeld DM. Consumption of cereal fiber, mixtures of whole grains and bran, and whole grains and risk reduction in type 2 diabetes, obesity, and cardiovascular disease. Am J Clin Nutr. 2013;98: 594-619.

36. Pham NM, Nanri A, Kochi T, Kuwahara K, Tsuruoka H, Kurotani K, Akter S, Kabe I, Sato M, Hayabuchi H, Mizoue T. Coffee and green tea consumption is associated with insulin resistance in Japanese adults. Metabolism. 2014;63:400-8.

37. Arnlov J, Vessby B, Riserus U. Coffee consumption and insulin sensitivity. JAMA. 2004;291:1199-201.

38. Dandona P, Ghanim H, Abuaysheh S, Green K, Batra M, Dhindsa S, Makdissi A, Patel $R$, Chaudhuri A. Decreased insulin secretion and incretin concentrations and increased glucagon concentrations after a high-fat meal when compared with a high-fruit and -fiber meal. Am J Physiol Endocrinol Metab. 2015;308:E185-91.

39. Tilg H, Moschen AR, Roden M. NAFLD and diabetes mellitus. Nat Rev Gastroenterol Hepatol. 2017;14:32-42.

40. Keijzers GB, De Galan BE, Tack CJ, Smits P. Caffeine can decrease insulin sensitivity in humans. Diabetes Care. 2002;25:364-9.
Ready to submit your research? Choose BMC and benefit from:

- fast, convenient online submission

- thorough peer review by experienced researchers in your field

- rapid publication on acceptance

- support for research data, including large and complex data types

- gold Open Access which fosters wider collaboration and increased citations

- maximum visibility for your research: over $100 \mathrm{M}$ website views per year

At BMC, research is always in progress.

Learn more biomedcentral.com/submissions 